\title{
Gradhiva
}

GRADHI

Revue d'anthropologie et d'histoire des arts

$2 \mid 2005$

Autour de Lucien Sebag

\section{Par Jean-Hubert Martin}

Jean-Hubert Martin

\section{(2) OpenEdition}

Journals

Édition électronique

URL : http://journals.openedition.org/gradhiva/527

DOI : 10.4000 /gradhiva.527

ISSN : 1760-849X

\section{Éditeur}

Musée du quai Branly Jacques Chirac

\section{Édition imprimée}

Date de publication : 1 novembre 2005

Pagination : 146

ISBN : 2-915-133-10-7

ISSN : 0764-8928

Référence électronique

Jean-Hubert Martin, «Par Jean-Hubert Martin », Gradhiva [En ligne], 2 | 2005, mis en ligne le 10 décembre 2008, consulté le 15 septembre 2020. URL : http://journals.openedition.org/gradhiva/527

Ce document a été généré automatiquement le 15 septembre 2020.

(c) musée du quai Branly 


\title{
Par Jean-Hubert Martin
}

\author{
Jean-Hubert Martin
}

1 Il n'est pas d'usage que les organisateurs d'une exposition répondent aux critiques. Mais lorsque le compte rendu, au lieu de donner un avis sur ce qui est donné à voir, s'emploie à décrire les antécédents de l'exposition et à spéculer sur les intentions des commissaires, on peut s'attendre à quelques rectifications.

2 L'exposition Magiciens de la terre voulait effectivement "montrer qu'il existait une création contemporaine dans les pays non occidentaux ». Je n'ai par contre jamais eu la naïveté eurocentrique de croire qu'elle pourrait «inspirer et insuffler une nouvelle dynamique en Occident ». Si ce genre d'idées a eu cours dans les années 1930 du temps de Georges-Henri Rivière, elles me semblent bien révolues.

3 Ma soi-disant "quête de spiritualité régénératrice " appelle la même remarque. Je ne fais au fil de mes expositions qu'essayer de décloisonner et d'ouvrir les yeux et les esprits. Le monde de l'art contemporain est nombriliste, étriqué et autosatisfait. Je cherche à repousser ses limites et à élaborer un système de jugement qui ne soit pas fondé sur l'exclusion, mais qui procure sa place à chaque création (religieuse ou pas) du monde d'aujourd'hui. Mes collègues d'Africa Remix ont été sans doute très surpris d'apprendre que notre exposition «ne se distingue pas radicalement "d'Altäre, que, selon toute vraisemblance, l'auteur de ces lignes n'a pas vue. Si les autels présentés dans l'exposition de Düsseldorf en 2001 étaient assimilés à l'art contemporain tel qu'il est montré dans Africa Remix, mes attentes les plus exigeantes seraient comblées !

4 Cette manifestation était annoncée comme une exposition d'art contemporain, un genre suffisamment connu pour qu'il soit superflu de l'affubler de la lapalissade d'« anhistorique ». Le catalogue pourtant ne se prive pas d'éclairer largement le lecteur sur les prémices et l'histoire dans laquelle l'auteur a puisé l'essentiel de ses informations (note 4 du compte rendu). Lorsque commence à s'enchaîner une certaine litanie de critiques rituelles, celle de la décontextualisation est inévitable. Rappelons que le propre du musée (et des expositions) est de collectionner des objets qui n'ont pas été faits pour lui (à l'exception de l'art occidental qui lui est contemporain). Une douzaine d'œuvres ont été commandées et créées pour cette exposition (et pas seulement celle de Cheick Diallo). J'attends toujours qu'on m'explique ce que serait une 
exposition contextualisée. Serait-ce de mettre quelques photos d'environnement et des textes « scientifiques » à côté des œuvres?

De même que les expositions ne peuvent susciter un contexte, elles ne visent pas forcément à donner une vision homogène d'une réalité. Elles peuvent au contraire vouloir mettre en valeur l'hétérogénéité de certaines pratiques artistiques sur le continent africain. C'est pourquoi tous les organisateurs d'Africa Remix n'ont eu de cesse d'insister dans leurs textes sur leur défiance vis-à-vis de toute « idée d'essence de l'art africain ».

\section{AUTEUR}

\section{JEAN-HUBERT MARTIN}

Jeanhubert.martin@stadt.dusseldorf.de 